\title{
Constructivism in patient education: using drawings to explore preconception of coronary artery disease
}

\author{
Katarzyna Nowicka-Sauer, ${ }^{1,2}$, Krzysztof Jarmoszewicz², Bartosz Trzeciak ${ }^{1}$, Krzysztof Roszak², \\ Adam Zemła ${ }^{2}$, Sebastian Beta ${ }^{2}$, Piotr Gutknecht ${ }^{1}$, Janusz Siebert ${ }^{1}$ \\ 'Department of Family Medicine, University Centre for Cardiology, Medical University of Gdansk, Gdansk, Poland \\ ${ }^{2}$ Department of Cardiac Surgery, Ceynowa Hospital, Wejherowo, Poland
}

Not everything that can be counted counts, and not everything that counts can be counted. Imagination is more important than knowledge. For knowledge is limited, whereas imagination embraces the entire world, stimulating progress, giving birth to evolution. It is, strictly speaking, a real factor in scientific research.

[Albert Einstein]

\section{INTRODUCTION}

The core principle of constructivism is the premise that learning is a process in which new knowledge is built upon existing knowledge. The preexisting cognitive model of a disease - preconception - is based on patients' experiences, intuition, and knowledge. Patients can also create misconception - an inconsistent view that needs to be identified and verified. Constructivism places patients as a centre of communication and prefers exploration, discussion, and questioning rather than learning ex cathedra [1, 2]. When providing patients with information, every clinician should be aware of a patient's perception of illness [1-3], which can be assessed using drawing $[4,5]$.

\section{METHODS}

The project of this exploratory, qualitative study was approved by the Ethics Committee of the Medical University of Gdansk. During face-to-face preoperative interviews performed by a clinical psychologist (K.N.-S.) on the day prior to surgery, patients were asked to draw their heart illness and to comment on their pictures. The drawings were analysed by three researchers (K.J., S.B., K.N.-S.). Structured interviews and medical chart reviews were used to gather socio-demographic and clinical data.

A total of 40 patients $(27.5 \%$ women; mean age 65.2 years) with coronary artery disease (CAD) scheduled for off-pump coronary artery bypass grafting (OPCABG) participated in the study. Exclusion criteria were patient's poor physical state and cognitive deficits (assessed using the Clock Drawing Test). Data of the patients are presented in Supplementary Table 1 and 2 (see journal website).

\section{RESULTS AND DISCUSSION}

Examples of patients' drawings are presented in Figure 1.

Thirty-eight drawings were analysed; two patients refused to draw their disease. Thirty-one (81.6\%) drawings depicted a heart or a heart with vessels. Vessels alone were depicted in six (15.8\%) pictures (Fig. 1, patient P.D.). One (2.6\%) drawing depicted a man with a cardiovascular system (Fig. 1, patient J.J.). Eleven (35.5\% of 31) patients drew "love hearts" (Fig. 1, patients L.B., K.S., J.P., J.R., M.C.). Three $(9.7 \%)$ patients used shading to illustrate the damaged heart (Fig. 1, patient J.P.). Two symbolic drawings depicted a "love heart": one with a schematic sad face (J.R.) and the other with a scar (K.S.). In all drawings showing vessels "blocked arteries" that cause "insufficient blood flow to the heart" were presented. On $12(46.2 \%)$ out of 26 drawings of heart-and-vessels, the vessels were placed within the heart (Fig. 1, patients L.B., M.O.), and on the remaining 14 (53.8\%) - outside it (Fig. 1, patients K.G., M.C.). The following misconceptions were identified: (i) patients placed coronary vessels outside the heart; (ii) "Bypass surgeries are open heart procedures, which means my heart has to be opened..."; (iii) "My heart will be stopped during the operation".

\section{Address for correspondence:}

Katarzyna Nowicka-Sauer, MA, PhD, Department of Family Medicine, Medical University of Gdansk, ul. Dębinki 2, 80-211 Gdańsk, Poland, tel: +48 5834915 75, fax: +48 5834915 76, e-mail: kpsauer@gumed.edu.pl

Received: 26.06.2018 Accepted: 12.07.2018

Kardiologia Polska Copyright (c) Polish Cardiac Society 2018 


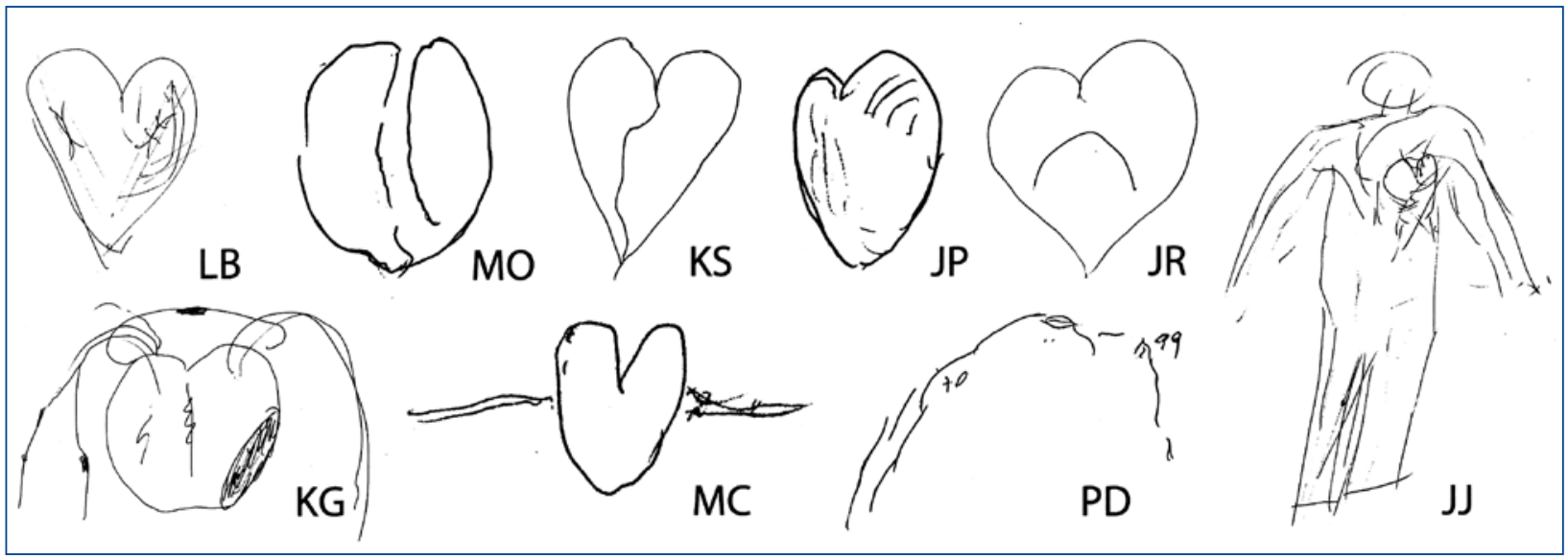

Figure 1. Drawings by patients representing their preconception of coronary artery disease. Patient L.B. "Two of my arteries are $100 \%$ blocked. They weren't able to put in a stent. From what I know, now during the surgery, they will go around the blocked spot"; Patient M.O. "The doctors said three vessels were blocked. The left side of my chest hurts, as if this part of my heart was in worse condition"; Patient K.S. "I'll have bypass surgeries done. How do I picture my disease? It's like I had a scar after a heart attack"; Patient J.P. "I had a heart attack. I know it's dangerous not to do the surgery. I imagine this side of my heart to be sort of bigger because my left ventricle is hypertrophied"; Patient J.R. "I can't imagine the exact heart disease.... I know the surgery must be done. It just makes me sad..."; Patient K.G. "This is how I picture it, there are vessels leading to the heart and they are blocked; the one on top is blocked completely. And this dark spot is a mark on my heart after the heart attack. It [the surgery] needs to be done, otherwise I'll drop dead"; Patient M.C. "I have no choice. I had a stent put in already in 2010. Now the doctor said a part is completely blocked and collateral circulation appeared already. The main danger lies in this forking. It is dangerous to me and that's why the surgery is needed"; Patient P.D. "The doctor showed me those blocked vessels on a monitor with a spike. I know one vessel is blocked in $70 \%$ and the other in 99\%... The doctor told me that he could try to unblock it but he didn't want to risk... he called the surgeon in. They agreed that the surgery is needed..."; Patient J.J. "I imagine that there is a cardiovascular system, let's say a system of vessels in our body going everywhere. And here is the heart. Some vessels are going to the heart, and in my body some of them are blocked".

Studies prove that prior to surgery patients declare a need for a broad range of information and that a lack of knowledge increases patients' anxiety [6, 7]. However, standard preoperative intervention may not be effective in cardiac surgery patients [8]. Our findings prove that a drawing-based interview is a useful way to assess patients' preconception of CAD. The vast majority of drawings were limited to a heart, a heart with blocked vessels, or vessels alone. The pictures seem to represent the belief that CAD is an "organ-limited" disease. Similar pictures were identified also in previous research [9-11]. A distinct, more global presentation of a disease was observed among women with chronic heart disease [9] as well as among patients with multi-organ autoimmune disease, such as systemic lupus erythematosus (SLE) [12]. These discrepancies may be related to the fact that, as was suggested, patients understood the illness "at a particular place and time" [13]. Not surprisingly, our inpatients' drawings were limited to an ill organ "just about to be operated on".

The analysis of drawings revealed some misconceptions: only two pictures illustrated anatomically shaped hearts, and in many drawings coronary arteries were placed incorrectly. Thus, it seems that information provided at the prehospital stage is insufficient. Weinman et al. noted that the heart was localised correctly by $50.5 \%$ of patients suffering from heart disease [14].

Our observations can be a clue to improvement of preoperative education and have important implications for clinical practice. It is useful to explore and verify patients' preconception of a disease. The invaluable benefit was patients' active involvement in the discussion, which facilitated patient-clinician communication.

\section{Conflict of interest: none declared}

\section{References}

1. Dennick R. Constructivism: reflections on twenty five years teaching the constructivist approach in medical education. Int J Med Educ. 2016; 7: 200-205, doi: 10.5116/ijme.5763.de11, indexed in Pubmed: 27344115.

2. Weidman J, Baker K. The cognitive science of learning: concepts and strategies for the educator and learner. Anesth Analg. 2015; 121(6): 1586-1599, doi: 10.1213/ANE.0000000000000890, indexed in Pubmed: 26579660.

3. Kiyohara LY, Kayano LK, Oliveira LM, et al. Surgery information reduces anxiety in the pre-operative period. Rev Hosp Clin Fac Med Sao Paulo. 2004; 59(2): 51-56, doi: 10.1590/S004187812004000200001 , indexed in Pubmed: 15122417.

4. Guillemin M, Drew S. Questions of process in participant-generated visual methodologies. Visual Studies. 2010; 25(2): 175-188, doi:10.1080/1472586x.2010.502676. 
5. Cheung MM, Saini B, Smith L. Using drawings to explore patients' perceptions of their illness: a scoping review. J Multidiscip Healthc. 2016; 9: 631-646, doi: 10.2147/JMDH.S120300, indexed in Pubmed: 27920550.

6. Hernandez-Palazon J, Fuentes-Garcia D, Falcon-Arana L. Visual Analogue Scale for Anxiety and Amsterdam Preoperative Anxiety Scale provide a simple and reliable measurement of preoperative anxiety in patients undergoing cardiac surgery. Int Cardiovasc Res J. 2015; 9(1): 1-6.

7. Nowicka-Sauer K, Banaszkiewicz D, Jarmoszewicz K, et al. Validation of the Amsterdam Preoperative Anxiety and Information Scale among patients scheduled for cardiac surgery. J Cardiovasc Surg (Torino). 2018; 59(3): 483-485, doi: 10.23736/S00219509.17.10106-0, indexed in Pubmed: 28870063.

8. Yildiz T, Gürkan S, Gür Ö, et al. Effect of standard versus patient-targeted in-patient education on patients' anxiety about self-care after discharge from cardiovascular surgery clinics. Cardiovasc J Afr. 2014; 25(6): 259-264, doi: 10.5830/CVJA-2014-048, indexed in Pubmed: 25363789.

9. Guillemin M. Embodying heart disease through drawings. Health (London). 2004; 8(2): 223-239, doi: 10.1177/1363459304041071, indexed in Pubmed: 15068638.
10. Nowicka-Sauer K, Jarmoszewicz K, Szyndler K, et al. How to express pain and illness? Using drawing for assessment of pain and illness among patients awaiting coronary artery by-pass grafting. Preliminary report]. Forum Medycyny Rodzinnej. 2015; 9(3): 288-290.

11. Broadbent E, Petrie KJ, Ellis CJ, et al. A picture of health: myocardial infarction patients' drawings of their hearts and subsequent disability: a longitudinal study. J Psychosom Res. 2004; 57(6): 583-587, doi: 10.1016/j.jpsychores.2004.03.014, indexed in Pubmed: 15596165.

12. Nowicka-Sauer K. Patients' perspective: lupus in patients' drawings. Clin Rheumatol. 2007; 26(9): 1523-1525, doi: 10.1007/s10067-007-0619-9.

13. Guillemin M. Understanding illness: using drawings as a research method. Qual Health Res. 2004; 14(2): 272-289, doi: 10.1177/1049732303260445, indexed in Pubmed: 14768462.

14. Weinman J, Yusuf G, Berks R, et al. How accurate is patients' anatomical knowledge: a cross-sectional, questionnaire study of six patient groups and a general public sample. BMC Fam Pract. 2009; 10: 43, doi: 10.1186/1471-2296-10-43, indexed in Pubmed: 19523189

Cite this article as: Nowicka-Sauer K, Jarmoszewicz K, Trzeciak B, et al. Constructivism in patient education: using drawings to explore preconception of coronary artery disease. Kardiol Pol. 2018; 76(8): 1274-1276, doi: 10.5603/KP.2018.0165. 